\title{
Prediking in 'n multimedia-kultuur. Homiletiese beginsels vir 'n interaktiewe kommunikasiepraxis
}

\begin{abstract}
Preaching in a multimedia culture. Homiletic principles for an interactive communication praxis

This article investigates the art of preaching culture from the perspective of the developing digital culture engulfing contemporary society. The demise of traditional preaching is discussed as problematic. A cursory investigation is launched into the impact of the developing digital culture on communication and homiletics. The attention then shifts to the communication model as developed by Heath and Heath, in their book, "Made to Stick." This model is subsequently adapted for the purposes of sermon preparatin and a digital-culture homiletic praxis.
\end{abstract}

\section{PROBLEEMSTELLING}

Dit word geruime tyd al gesê dat erediens en kansel openbare invloed verloor en in die spervuur van kritiek staan. Enersyds word gesê dat die erediens mense nie meer aanspreek nie omdat dit 'n versteende, selfs verstarde kleed uit die verlede aangetrek hou en nie pas by moderne beweeglikheid nie (Barnard 1981:4). Die manier waarop die kerk kommunikeer, het vir die meeste mense dood gegaan of betekenisloos geraak as "impotent mouthings" (Buttrick 1987:5). Boonop is gevind dat min preke relevant genoeg is om die evangelie as ' $n$ krag van verandering voor te hou (Cilliers 1996:3). Die "arsenaal besware" wat in hierdie verband geopper word, wissel van vergelykings tussen predikers en openbare sprekers; predikers wat 'n ooraanbod van inligting gee en 'n semantiese geruis veroorsaak; die preek as wyse van kommunikasie in kontras met die informasie-aanbod deur moderne kommunikasie-netwerke; en uiteindelik word gekla dat die tydlose boodskap van die Bybel irrelevant geraak het vir moderne mense (Vos 1995:1-3). Uiteindelik word die laat-moderne kultuurverandering wat sedert die twintigste eeu plaasvind en nog teen versnellende tempo voortduur, uitgelig as oproep tot die transformasie van die erediens (Gibson 2004:11).

Die multimedia-ontploffing op die gebiede van satelliettelevisie en veral die internet word uitgesonder as "sondebokke" in die aftakeling van die krag van die prediking: Die laaste vyftig jaar het hierdie tegnologieë bygedra tot die aanhoudende en onophoudelike transformasie van die kulturele vesel van die samelewing, is die dinamika van verhoudings geskuif en is die wyse van inligtingsoordrag in die senuweestelsel van die brein verander (Babin 1991:55; Miller 2004:1). Die impak van hierdie transformasie is van so 'n omvangryke aard dat daar van 'n ekklesiologiese paradigmaskuif gepraat word (Mead 1991:85).

Dit word aangevoer dat een van die teologiese uitdagings in hierdie tyd die uitbou van die leerbediening in die kerk is, spesifiek 'n herlewing in prediking en aanbidding (Osmer 1990:4-5). Die Christendom leef inderdaad teen die agtergrond van woorde: God het die wêreld tot bestaan gespreek, die Woord het vlees geword en goeie nuus kom sê, en die kerk word gebou op die 
getuienis van apostels, martelaars vir die geloof en heiliges (Buttrick 1987:5-6) en die getuienis van die geloofsgemeenskap vind onder andere plaas wanneer die eer en heerskappy van God korporatief besing word. Daarom moet die evangelie in elke generasie op so 'n manier oorgedra word dat dit die lig op 'n ander manier reflekteer. Hierdie spreek van die evangelie vir elke nuwe kulturele tydperk is 'n teologiese aktiwiteit (Buttrick 2007:10).

Inderdaad is hierdie teologiese aktiwiteit ' $n$ missionêre een. Nie alleen is die Christelike geloof intrinksiek missionêr nie (Bosch 1991:8), dit is ook ' $n$ deelname aan God se besig-wees met die wêreld, aan sy liefdevolle besluit om die gebroke skepping te genees. In die sentrum van die kerk se deelname aan hierdie missio Dei staan die kommunikasie van die evangelie (Güder 2000:49). Calvyn (1956:461) skryf in hierdie verband tereg dat die prediking van die evangelie niks anders uitspreek nie as dat sondaars deur die Vaderlike genadigheid van God buite hulle eie verdienste geregverdig word en die hoofinhoud hiervan eindig in Christus.

Die intensie van prediking is daarin geleë om oortuiging te wek, God as 't ware vir hoorders aan te bied, of Hom aan hulle voor te stel (Marty 2007:100). Prediking raak immers die hele geloofsgemeenskap aan en beweeg hulle, in hulle bepaalde konteks as God se geroepenes, in God se rigting (Nel 2001:5). En prediking stel die Bybel aan gelowiges voor op 'n manier wat lewens verander en nie bloot inligting in mense se verstand indruk nie (Cilliers 1996:115; Peterson 2006:3). As sodanig beskik prediking oor 'n missionerende kwaliteit.

Hierdie artikel fokus gevolglik op die missionale kommunikasie van die evangelie in ' $n$ multimedia kultuur. Vir hierdie doel word ondersoek ingestel na 'n kommunikasiemodel van Heath en Heath (2008), met die oog op prakties-teologiese toepassing. Die ses hoofbewegings van hierdie kommunikasiemodel lyk soos volg (Heath \& Heath 2008:257):

Eenvoud: $\quad$ om die kernidee van ' $n$ tema vas te vang.

Onverwags: om hoorders te laat aandag skenk aan die kernidee.

Konkreet: om die kernidee verstaanbaar en memoriseerbaar te maak vir hoorders.

Geloofwaardig: om hoorders in die kernidee te laat glo en daarby te laat inkoop.

Emosioneel: om hoorders te laat omgee.

Narratief: $\quad$ om hoorders te laat optree.

\section{PREDIKING IN 'N MULTIMEDIA-KULTUUR}

Die twintigste-eeuse ontwikkeling van die televisiestel, maar veral die rekenaar, het uitgeloop op 'n ontploffing in wetenskaplike ontdekkings en tegnologiese ontwikkeling. Onder die gemeenskaplike noemer Informasie Tegnologie behels hierdie tegnologie die manipulasie van groot hoeveelhede inligting op'n uiters klein skaal. Die oorskakeling van'n nywerheidsgebaseerde ekonomie na 'n informasie-gedrewe ekonomie is so omvangryk dat daar van 'n informasie rewolusie gepraat word (Saxby 1990:1): Dit het die manier waarop mense besigheid doen en werk, verander; dit affekteer verhoudings en verhoudingsnetwerke tussen mense; dit het die wyse waarop inligting ingeneem, geskep en verwerk word verander; en dit het ' $n$ vloedgolf van nuwe eise en uitdagings oor die mensdom laat spoel wat nog nie tot stilstand gekom het nie, grootliks omdat rekenaartegnologie daarin geslaag het die wyse waarop menslike interaksie plaasvind, fundamenteel te verander (Saxby 1990:3).

Tans is dit moontlik om te kommunikeer deur telefoon, selfoon en internet. Mense stuur teksboodskappe aan mekaar deur internetgebaseerde diensnetwerke soos Facebook, Twitter, Mxit of Skype. Digitale rekenaarkameras maak direkte aangesig tot aangesig kommunikasie oor die internet moontlik vir mense op verskillende plekke in die wêreld. Meer belangrik, egter, is die verskynsel dat hierdie tegnologie binne 'n enkele dekade daarin geslaag het om 'n hoeksteen van die ontwikkelende kultuur te word. Gevolglik word die mensdom daagliks gebombardeer met 
inligting. Nie alleen is die tradisionele televisie, radio, koerant en tydskrif steeds beskikbaar nie, dit is uitgebrei met ' $n$ permanente vloei van nuus en inligting deur die internet.

Een van die uitstaande kenmerke van 'n multimedia samelewing is die toenemende behoefte aan die beskikbaarheid van inligting as grondslag vir besluitneming (Pettersson 1989:33). As gevolg van die ontwikkeling van multimedia-tegnologieë wat televisie en rekenaar met mekaar verbind, vind ' $n$ radikale omwenteling in kommunikasie plaas - kommunikasie is nie langer net verbaal en kognitief gerig op die oordrag van feite nie, dit is ook oudio-visueel en emosioneel gerig op die verkryging van effek.

Hierdie ontwikkeling is veral gestimuleer deur navorsing oor die hemisferiese verdeling van die brein: Elke breinhelfte beskik selfstandig oor sensoriese persepsies, gedagtes, gevoelens en herinneringe alhoewel die brein albei hemisfere op gelyke wyse aanwend (Pettersson 1989:76). Die linkerhemisfeer van die brein funksioneer grootliks verbaal, met die vermoë tot spraak rekene en skryf, spesialiseer in abstrakte denke en analities, logies, gedetailleerd, sekwensieel en lineêr funksioneer. Dis gekontroleerd, dominant en krities, beskik oor gevestigde simboolverrekeningsvermoë, herken maklik positiewe emosies, is doelwitgeoriënteerd en leer by wyse van ontwikkeling. Dit is boonop tydsensitief, aggressief en beheer die regterkant van die liggaam.

Die regterhemisfeer van die brein is sonder spraak, maar in staat tot konkrete denke, huisves die persepsie van ruimte en het 'n begrip vir gekompliseerde verhoudingsnetwerke. Dit is holisties, spatiaal, intuïtief, kreatief en ontvanklik. Dit het die vermoë om met nuwe simbole te werk, nuwe gesigte te onthou en inligting en negatiewe emosies te hanteer. Dit is kunstig, interpreteer hoorbare seine, emosionele ondertone en musiek. Dit verafsku tyd en boonop is hierdie hemisfeer geheel en al dominant bo die linkerhemisfeer in die waarneming van twee- en driedimensionele beelde. Die regterhemisfeer kontroleer die linkerkant van die liggaam.

Die verhouding tussen die twee breinhelfte kan soos volg opgesom word (Babin 1991:55):

\begin{tabular}{|l|l|}
\hline $\begin{array}{l}\text { LINKER HEMISFEER } \\
\text { (Beheer regterkant van liggaam) }\end{array}$ & $\begin{array}{l}\text { REGTER HEMISFEER } \\
\text { (Beheer linkerkant van liggaam) }\end{array}$ \\
\hline Spraak en verbaal & Ruimte-georiënteerd, musikaal \\
Logies en wiskundig & Holisties \\
Lineêr en gedailleerd & Kunstig, simbolies \\
Sekwensieel & Gelyktydig \\
Gekontroleerd & Emosioneel \\
Intellektueel & Intuïtief, skeppend \\
Dominerend & Stil \\
Aards, konkreet & Spiritueel, godsdienstig-simbolies \\
Aktief & Ontvanklik \\
Analities & Sinteties, beeldend \\
Lees, skryf, naamgee & Herkenning van gesigte \\
Opeenvolgende ordening & Gelyktydige begripsverkryging \\
Persepsies van betekensivolle orde & Persepsie van abstrakte modelle \\
Komplekse motoriese sekwense & Herkenning van ingewikkelde beelde \\
\hline
\end{tabular}

In die modernistiese paradigma van die Westerse kultuur is voorrang gegee aan die funksionering van die linkerbreinhemisfeer. Dit het uitgeloop op ' $n$ inperkende burokrasie met die oordrewe fokus op reëls en regulasies waarin die ontwikkeling van nuwe idees effektief gekniehalter is (Pettersson 1989:77-78). Die gevolg is 'n samelewing waarin die heersende kultuur, waardestelsel en etiese norme toenemend deur beelding bepaal word eerder as regulering. Hierdie "broadcast 
world" is geïnteresseerd in wat mense nie weet nie, omdat ' $n$ vloed van vars beelde die mensdom se eens-gevestigde denkpatrone oorspoel met 'n appél op die sensoriese (Miller 2004:76-77): Die nuwe digitale wêreld is besig om ons begrip van tyd en geskiedenis te verander, want dit trek die toekoms binne-in ons onmiddellike bewussyn in en tap die beste uit die verlede op gelyktydige wyse. Die interaktiewe aard van digitale kommunikasie het inderdaad 'n dors na dieper konneksie laat by mense opborrel.

Die digitale kultuur het die volgende implikasies (Miller 2004:78):

- Die digitale kultuur se begeerte vir direkte, ongekontroleerde, eerstehandse ondervinding is besig om die gedrukte media en televisie se passiewe gestalt te vervang.

- $\quad$ Die digitale kultuur se afhanklikheid aan netwerke en persoonlike verhoudings is besig om televisie se vooroordeel ten gunste van kollektiewe hooftema-ondervindings te vervang.

- Die digitale kultuur se ope-bron tegnologieë (soos Wikipedia), organisasies en denke is in die proses om die gedrukte media en televisie se handelsmerkskepping en eiendomsregtelike aansprake omver te werp.

- Die digitale kultuur se vermoë om die verlede te herbesoek is besig om gedrukte media en televisie se verwerping van die verlede vervang.

- Die paradigma-gebasseerde benadering tot komplekse kwessies en konflik van die digitale kultuur is besig om die politieke benadering van gedrukte media en televisie te vervang.

- $\quad$ Die multimedia taal van die digitale kultuur is besig om gedrukte media en televisie se visuele taal te vervang.

- $\quad$ Die digitale kultuur se integrasie van linker- en regterbrein prosesse vervang gedrukte media en televisie se afhanklikheid van regterbrein denke.

Die belangrikste verwikkeling is egter dat die digitale generasie die wêreld deur'n stel dinamiese modelle begin filter wat die algemene gedrag van komplekse sisteme beskryf, ontdek en plaas om in verhoudings en situasies toe te pas. Dit staan bekend as sisteemdenke (Miller 2004:81). Sisteemdenke is 'n dissipline om geheelbeelde te ondersoek (Senge 2006:68). Dis 'n raamwerk wat interverhoudings raaksien eerder as oorsaak-gevolg kettings en wat patrone van verandering identifiseer eerder as om op statiese gebeurtenisse te fokus. Deur sisteemdenke kan die onderliggende strukture van komplekse situasies raakgesien word en op hierdie wyse word 'n taal gegee wat kan begin om dit wat ons dink te herorganiseer (Senge 2006:69).

Tegelyk moet aanvaar word dat mense toenemend die plaaslike gemeente verlaat, hoewel hulle lewens die lewe en doestellings van Christus reflekteer en die koninkryk van God bevorder (Barna 2005:7). Die veranderende sosiale kultuur (waar die invloed van die moderniteit erodeer voor die invloedsgolf van 'n aanspoelende postmoderne kultuur), modernistieseera eredienspraktyke, bedieningstrukture en geloofsgewoontes van hoofstroomkerke, en derdens die geloofsontwikkeling van lidmate binne hierdie kerke wat toenemend in 'n namoderne kultuurmilieu funksioneer, oefen ingrypende invloed uit op die bediening van die plaaslike gemeente - die besinning oor prediking in 'n multimedia kultuur ingesluit (Jamieson 2002:16). Hierdie veranderende kultuur sien 'n hele nuwe generasie mense wat kerk toe gaan om die werklikheid van hulle geloof te beleef voor hulle oor die inhoud nadink; deelneem aan die lewe van die kerk voordat hulle eers instemming betoon met die betekenis van geloof in Christus; en wat die waarhede van Christus uitleef voor hulle dit aanvaar as ewige waarheid (Sweet 1999:215). Die kerk het as 't ware 'n nuwe sendingveld betree omdat sy die taal van die opkomende generasie moet aanleer om die goeie nuus van Jesus se verlossing te vertel in ' $n$ idioom van nie-verbale, simboliese kommunikasie (Richter 1998:80-81).

Hierdie veranderende konteks pleit om groter deelname aan die bediening van die gemeente 
deur alle gelowiges. Die markplein-beweging na verpersoonlikte deelname en self-organisering in besluitneming en die sosiale dinamika van mense wat saam beter besluite neem as alleen, spoel ook oor na die kerklike kultuur en kerklike leierskap (Morgenthaler 2007:178). Verhoudings regeer die nuwe sosiale dinamika (Sweet 1999:195). Die homileties-liturgiese uitdaging is gevolglik om spanne te vestig wat saam werk om ruimtes te vorm waarbinne die Heilige Gees outentieke ondervindings van God kan skep (Sweet 1999:211). Om Sweet (1999:213) self aan die woord te stel: "Postmodern evangelists are electricians - they go around wiring people to the Spirit, getting them connected to holy energies. The power of connectedness is this: The more connections there are in a system, and the greater the strength in those connections, the greater the intelligence and the greater the consciousness."

Die wegspringpunt vir 'n interaktiewe kommunikasiepraxis word gevind in die plaaslike gemeente. As lewende organisme word elke lidmaat van die kerk uit die gehoor uitgeroep om rolspelers te wees-elke gelowige speel'n noodsaaklike rol in die drama van verlossingsgeskiedenis, daardie drama wat deur God geskryf word (Ogden 1990:19). Chan (2006:14) praat hiervan as 'n teologiese ekklesiologie waar die gemeente funksioneer in ' $n$ "perchoretiese" eenheid met die Drie-Enige God deur die Gees. Op hierdie wyse verkry die kerk haar ware merkteken as die kerk van Christus en word die visie van die kerk as 'n ontologiese werklikheid vasgelê.

Erediens en prediking kan geplaas word in 'n raamwerk van liturgiese diversiteit binne die plaaslike gemeente. Gemeentes wat die swaarste gebuk gaan onder die impak van die veranderende kultuur, is dié wat vasgevang bly in 'n "one-size-fits-all approach, typically proving that one-size-fits-nobody" (Barna 2005:63). Eie aan die dubbelring-klimaat van hierdie era, waar teenstrydige sake harmonieus naas mekaar kan bestaan (Sweet 1999:27), is dit noodsaaklik om liturgiese diversiteit in een gemeente te verreken.

Derhalwe kan eredienste vir die opkomende generasie (vgl Wepener 2009b:181) in 'n interaktiewe kommunikasiepraxis skematies soos volg geplaas word (Smit 2010:4):

\begin{tabular}{|l|l|l|}
\hline \multicolumn{1}{|c|}{ Tradisioneel } & \multicolumn{1}{|c|}{ Gesinsdiens } & \multicolumn{1}{c|}{ Opkomende Generasie } \\
\hline $\begin{array}{l}\text { Formele liturgie } \\
\text { Sang met klassieke } \\
\text { begeleiding (orrel) }\end{array}$ & $\begin{array}{l}\text { Informele liturgie } \\
\text { Sang met voorsanggroep }\end{array}$ & $\begin{array}{l}\text { Onsigbare liturgie } \\
\text { Sangbegeleiding reflekteer } \\
\text { kultuurbelewenis van die } \\
\text { opkomende teikengroep }\end{array}$ \\
\hline $\begin{array}{l}\text { Praktyk-gerigte prediking wat } \\
\text { fokus op die fasilitering van 'n } \\
\text { ontmoeting met God }\end{array}$ & $\begin{array}{l}\text { Praktyk-gerigte } \\
\text { prediking wat fokus op } \\
\text { die fasilitering van 'n } \\
\text { ontmoeting met God } \\
\text { Min simbole en ritueel }\end{array}$ & $\begin{array}{l}\text { Eksperimentering met } \\
\text { set interaktiewe deelname } \\
\text { deur gehoor }\end{array}$ \\
\hline
\end{tabular}

\section{'N INTERAKTIEWE KOMMUNIKASIEPRAXIS}

'n Intieme verhouding bestaan tussen liturgie en prediking. Dit is veral in die gereformeerde lewensgevoel sigbaar as geglo word dat "die 'lewende God en sy Christus' ... by ons aanwesig is nié in die kerk self nie, en nié in ons eie subjektiewe gevoelens nie, maar deur die Heilige Gees, wat deur die beloftes van die gepredikte Woord, verseël deur die sakramente, geloof in ons hart werk" (Smit 2009:100). Gevolglik kan liturgie verstaan word as die ontmoeting tussen God en mens waarin God en mens na mekaar toe uitreik, met God in die primêre hoedanigheid, sodat dialogiese kommunikasies in en deur rituele en simbole gevestig word waaraan mense fisies 
deelneem en God op hierdie manier die lof toesing (Wepener 2009a:21). In hierdie teonomiesresiproke ontmoeting is die preek daardie element van die erediens waarin die predikant - as hoorder onder die hoorders - as fasiliteerder optree in mede-kerkgangers se eie kommunikasie met die evangelie en agter dit hulle kommunikasie met God self (Dingemans 1991:50).

- Burger (2009:21-26) bied vier teologiese perspektiewe op die belang van die erediens:

- In die erediens kom mense in die teenwoordigheid van die lewende, opgestane Christus.

- $\quad$ Die erediens is die plek waar die Here sy seën en verlossing aan ons meedeel en deur die werk van die Gees in ons lewens indra.

- Die erediens is die plek waar ons die stukkendheid en patos van ons lewens voor die Here bring.

- $\quad$ Dit is die plek waar die Here ons laat tuiskom en deel maak van sy oop, sorgende familie. 'n Duidelike perspektief op die gemeenskaplike aard en karakter van erediens en prediking tree hiermee na vore. Die erediens is 'n ontmoetingsgebeurtenis tussen 'n geloofsgemeenskap en die lewende God. Omdat God die hele gemeente roep om die evangelie te verkondig, is die erediens en prediking 'n element van die gemeente se bedieningstaak (Long 1989:12).

Dit is waardevol vir die homiletiek om die basiese beginsels van die kommunikasieproses te verdiskonteer: Aangesien Praktiese Teologie sigself verstaan as kommunikatiewe handelinge, speel kommunikasiebenaderings wat deur die kommunikasiewetenskappe ontwikkel is, in veral die homiletiek 'n betekenisvolle rol (Barna 1995:138-139). Die groeiende besef dat die kerk ' $n$ medewerker is in die missio Dei oefen ook'n invloed uit op die wesensverstaan van die erediens. Veral word aanbidding gesien as die sentrale, openbare handeling waardeur Christelike gemeenskappe God se teenwoordigheid en beloofde toekoms met vreugde en danksegging vier (Niemandt 2007:141). Dit spruit uit so 'n ontwikkelende ekklesiologie voort dat die kerk 'n verbondsgemeenskap is, gesentreer op Jesus as die Bemiddelaar van die nuwe verbond met God. As sodanig word die episentrum van die Christelike geloof gevind waar gemeentes deelneem aan die verlossing wat Christus bring (Hirsch 2006:40-41). Hoewel die erediensbediening van 'n gemeente nie die somtotaal mag vorm van die gemeente se missionêre medewerking aan God se sending na die aarde nie, bly die erediens die vertoonvenster van die gemeente: Dit is in baie opsigte steeds die hartklop van 'n gemeente omdat dit die grootste saamtrek is van gemeentelede en uitdrukking gee aan die kern-aspek van kerkwees - om God te verheerlik en Sy teenwoordigheid in die lewens van sy kinders te vier (Richter 1998:5).

Tog blyk dit dat eiesoortige eise aan erediens en prediking in 'n multimedia kultuur gestel word. Kommunikasie in die ontluikende konteks stel ander eise, en funksioneer in 'n onbekende paradigma. Dit veronderstel die inoefening van nuwe vaardighede om die eeue-oue boodskap van God se besig-wees deur Christus te laat vassteek by informasievoos hoorders en steeds te voldoen aan die teologiese verwagting wat aan die prediker gestel word.

\section{OP SOEK NA EENVOUD}

Die soeke eenvoud beteken gewoon om die kern van 'n idee - oftewel dit die belangrikste aspek van die idee verwoord - te identifiseer (Heath \& Heath 2008:27). Dit is die gevolg van die besef dat verbale kommunikasie geneig is om te lank te wees en te veel inligting oor te dra, terwyl gehore passief is wat daartoe lei dat hulle verwar word omdat hulle nie om verheldering kan vra nie (Atkinson 2008:5-6). Deur 'n joernalistieke metafoor te benut - "finding the lead" word ' $n$ proses van gedwonge prioritisering beskryf om dit te bereik (Heath \& Heath 2008:32). Gedwonge prioritisering vind plaas wanneer die spreker die belangrikste aspek van 'n voordrag identifiseer en sy/haar voorlegging daar rondom bou. In die prediking gebeur dit wanneer die prediker die Bybelteks toelaat om as leidende krag in die vormgewing van die inhoud en doel van die preek op te tree (Long 1989:48). 
Gedwonge prioritisering word gevind in die erkenning dat die preek ' $n$ kunsvorm is waar die prediker se verbeelding 'n kernaspek uitmaak van 'n inkarnasioneel-kunstige hermeneutiek (Hunter 2007:93-94). Dit word verwesenlik deur laterale denke. Laterale denke kan omskryf word as ' $n$ manier om konseptuele patrone wat deur tradisionale denkprosesse ontwikkel is, te herstruktureer en nuwe alternatiewe te ontdek (De Bono 1970:13). Gevolglik is laterale denkprosesse gefokus op veranderende patrone, op die verskaffing van bykomende inligting wat georganiseer moet word sodat geykte organisasiepatrone wat deur die menslike brein geskep word, bevraagteken en verhelder kan word (De Bono 1970:48-51). Die proses om die kern van 'n preek vanuit 'n preekteks deur gedwonge prioritisering te vind, word dus deur laterale denke bevorder. In hierdie verband kan 'n laterale denksiklus wat die proses van gedwonge prioritisering in prediking kan verhelder, onderskei word (Skinner 1993:112):

- $\quad$ Ontginning van persoonlike kreatiewe potensiaal en verwerking van die inligting.

- Kreatiewe konneksie van verhoudingsnetwerke van hierdie inligting en konsepte.

- 'n Tydperk van onbewuste inkubasie.

- Intuïtiewe insigverkryging.

- $\quad$ Afronding van die proses deur die teologiese verifikasie van die kerninsig.

\section{ONVERWAGSHEID}

Onverwagsheid het te make met die spreker se vermoë om geykte denkpatrone te deurbreek (Heath \& Heath 2008:64). Dit bevorder die geloofwaardigheid van die boodskap en keer dat die spreker die kernpunt verloor en die gehoor verwar (Davis 1991:20, 51). Dit word verwesenlik deur benutting van die elemente van verrasssing (omdat dit mense se aandag trek - mits dit met die oog op verkryging van insig gebruik word) en belangstelling (omdat dit mense se aandag behou) (Heath \& Heath 2008:65).

\section{KONKREETHEID}

"Language is often abstract, but life is not abstract" (Heath \& Heath 2008:99). Abstraksie veroorsaak dat 'n idee moeiliker begryp word. Daarom baat dit 'n kommunikeerder om op konkrete taalgebruik terug te val wanneer hy/sy nie seker is wat mense weet wanneer sy/hy begin om 'n idee te verduidelik nie (Heath \& Heath 2008:104). Hierdie soeke na konkreetheid word gevind deur die vasstelling van die rigting van die boodskap en die primêre argumente wat gevoer moet word (Murphy 1997:83). Die volgende sake word aan die orde gestel in die konkretisering van die boodskap (Murphy 1997:83-84):

- $\quad$ Stel ' $n$ bondige verduidelikende stelling op van die kern van die boodskap.

- Verfyn die stelling deur konsultasie met medewerkers aan die erediens.

- $\quad$ Stel vas wat die hoorders hieroor moet weet en wat hulle hiervolgens moet doen.

\section{GELOOFWAARDIGHEID}

In die huidige multimedia kulturele milieu word mense so gebombardeer met inligting dat hulle skepties geraak het oor die bronne van hierdie informasie, dat geloofwaardigheid aan idees verleen word deur die volgende (Heath \& Heath 2008:136-157):

- Die outoriteit van vriende - Op hierdie manier word geloofwaardigheid gebaseer op die eerlikheid en betroubaarheid van hierdie bronne eerder as hulle status, of posisie in die samelewing;

- Die krag van besonderhede - dit verleen interne geloofwaardigheid aan die idee self in 
plaas van die kommunikeerder wat die idee oordra (Heath \& Heath 2008:138);

- Die benutting van statistiek - die voorbehoud hierin is dat statistieke insigself betekenisloos is, maar wanneer dit gebruik word om 'n spesifieke verhouding met betrekking tot die idee aan te dui (Heath \& Heath 2008:143), wanneer dit gekontekstualiseer word deur ' $n$ analogie in alledaagse, menslike terme te trek (Heath \& Heath 2008:145), en wanneer dit gebruik word as kreatiewe inset in die vormgewing van 'n idee eerder as argument ter ondersteuning van die idee (Heath \& Heath 2008:147), word dit effektief benut;

- Die benutting van 'n enkele, onderskeidende voorbeeld wat insigself sterk genoeg is om die geloofwaardigheid van 'n idee te vestig ((Heath \& Heath 2008:151); en laastens

- Falsifieerbare geloofwaardigheid deur die hoorders, oftewel, "sien vir jouself" (Heath \& Heath 2008:157).

\section{EMOSIONALITEIT}

Emosionaliteit word nie verstaan as gevoelsmatige opsweping of eksploitering nie, maar die ontginning van hoorders se vermoë om werklik om te gee (Heath \& Heath 2008:168). Drie strategieë om mense daartoe te beweeg om om te gee kan geïdentifiseer word:

Assosiasie. Hierdie vermoë word aangevuur deur 'n assosiasie te skep tussen iets waarvoor mense nog nie omgee nie en iets anders waarvoor hulle inderdaad omgee (Heath \& Heath 2008:173).

Eiebelang. Heath en Heath (2008:182-184) omskryf hierdie assosiasie sielkundig van naderby aan die hand van Maslow se teorie van behoeftes. Volgens Maslow (1943) word mense gemotiveer deur 'n kombinasie van behoeftes wat wissel van fisieke behoeftes as mees basiese behoefte tot die behoefte aan transendensie as mees ontwikkelde behoefte.

Identiteit. Naas eiebelang speel groepsbelang ook 'n bepalende rol in mense se vermoë om om te gee (Heath \& Heath 2008:189). Hierdie groepsbelang vorm die grondslag van mense se kollektiewe identiteit en dryf hulle om in die belang van mense wat soos hulle is, volgens hul eie definisie, op te tree. Die vraag "what would someone like me do?" word gevra.

\section{NARRATIEF}

Verhale is effektiewe hulpmiddels in die leerproses (Heath \& Heath 2008:205-206): Dit help mense om te sien hoe konteks hulle kan mislei om verkeerde besluite te neem. Dit illustreer informele verhoudings wat nie voorheen ge-eien is nie en dit lig onverwagse, innoverende maniere uit waarmee mense probleme opgelos het. Die krag van 'n verhaal is tweërlei: Dit bied stimulering (oftewel kennis oor hoe om op te tree) en inspirasie (motivering om op te tree). Beide voordele het ten doel om aksie te genereer.

'n Narratiewe proses wat die natuurlike vloei van die Bybeldrama volg, is die gekose meganisme om die narratief in ' $n$ preek te aktualiseer: "Like a good story, the Bible presents the problem, slowly demonstrates its power to undo the main characters and then takes our breath away with the sudden turn of events that shocks us with unexpected grace" (Belcher 2009:155). Die indikatief lei gevolglik tot die imperatief. Dit is die sleutel tot ' $n$ goeie storie, sentraal tot die Bybel en in die hart van prediking wat relevant, aangrypend evangelie-gesentreerd en inspirerend is. Hierdie tegniek ontsluit 'n "aha-oomblik" - die lewensveranderende transformerende krag van God se verrassende genade deur Christus en die nuwe lewe wat Hy bring (Belcher 2009:156); Belcher praat hiervan as 'n "Christ-centered homiletical plot."

'n Hedendaagse hulpmiddel in die vaslegging van hierdie "aha-oomblik" is die benutting van videogrepe en ander digitale vorme van simboliese kommunikasie (Sellers 2004). Die aantal 
individue wat digitale kommunikasie gebruik as primêre bron van inligting en kommunikasie groei teen so 'n tempo dat dit kan aanleiding gee tot 'n reeks rewolusionêre veranderinge wat organisasies en instellings forseer om by die nuwe kultuur aan te pas eerder as om dit te akkommodeer (Miller 2004:78). Deur die inkorporering van digitale media slaag predikers daarin om hulle narratiewe te vermeng met konkrete verhale uit die gedeelde ervaringswêreld van die hoorders sodat dit kruis met die ontvouende, voortgaande verhaal van God (Sweet, McLaren \& Haselmayer 2003:207).

\section{GEVOLGTREKKING}

Uit hierdie bondige bespreking is dit duidelik dat 'n intensioneel-laterale ontwikkelingsproses noodsaaklik is om effektief te kommunikeer in die digitale kultuur. Die kommunikasie-model wat deur Heath en Heath voorgehou word, slaag daarin om 'n homiletiese praxis te vestig waarin prediking op 'n visuele en simboliese manier tot hierdie kultuur kan help spreek.

Dit is egter nodig om verder in te vra na die verhoging van deelname deur die hoorders van 'n preek. In die digitale kultuur het 'n interaktiewe imperatief ontwikkel wat luisteraars permanent getransformeer het van passiewe ontvangers van inligting tot integrale deelnemers aan die kommunikasieproses. Die sentrale rol wat digitale kommunikasie - selfoontegnologie, internetgebaseerde sosiale media en die nuwe sentraliteit van simboliese kommunikasie - in hierdie proses speel, moet eweneens teologies verreken word.

Uiteraard kan 'n sosiologiese kommunikasiemodel nie op lineêre wyse as' $n$ homiletiese teorie aangebied word nie. Die risiko om die preek te verskraal tot 'n effektiewe voordrag sonder dat die intrinsieke aard van die geloofsgemeenskap en die deelname van die hoorders as gevolg van hulle verbintenis aan die gemeente, of die hermeneutiese proses en eie-aard van die brontekste verreken word, is te groot. Heath en Heath se model kan dus dien as ' $n$ aanvullende teorie om die finale vorm van die homiletiese boodskap te kontroleer aan die hand van die kenmerke wat hulle vir effektiewe kommunikasie geïdentifiseer het. ' $n$ Mens moet altyd in gedagte hou dat die benadering tot kommunikasie bepaal word deur die doelwit met die kommunikasie (Stanley \& Jones 2006:100): In prediking is die doel met kommunikasie lewensverandering. Meer bepaald is die doel met prediking om mense te leer hoe om ' $n$ lewe te lei wat die waardes, beginsels en waarhed evan die Bybel reflekteer. Die benutting van die kommunikasiemodel soos deur Heath en Heath ontwikkel, moet dus heeltyd gekorrigeer word deur hierdie onderliggende motief.

\section{BRONNELYS}

Atkinson, M. 2008. Speech-making and Presentation Made Easy. Seven essential steps to success. London: Vermilion.

Babin, P. 1991. The New Era in Religious Communication. With Mercedes Iannone. Minneapolis: Fortress Press.

Barna, G. 2005. Revolution. Finding Vibrant Faith Beyond the Walls of the Sanctuary. Carol Stream: Tyndale House Publishers.

Barnard, A.C. 1981. Die Erediens. Pretoria: NG Kerk Boekhandel.

Belcher, J. 2009. Deep Church. A Third Way beyond Emerging and Traditional. Downers Grove: IVP Books. Bosch, D.J. 1991. Transforming Mission. Paradigm Shifts in Theology of Mission. New York: Orbis Books. Burger, C. 2009. “Ontdek die belang van die Erediens.” In: Ontdekkings in die Erediens. Wellington: Lux Verbi.BM. p.p. 15-29.

Buttrick, D. 1987. Homiletic. Moves and Structures. Philadelphia: Fortress Press.

Buttrick, D.G. 2007. "Preaching Today: The Loss of a Public Voice." In: The Folly of Preaching. Models and Methods. Grand Rapids: William. B. Eerdmans Publishing Company. p.p. 3-14.

Calvyn, J. 1956 (zesde druk). Institutie of Onderwijzing in de Christelijke Godsdienst. Deel Een, Boek II. 
Vertaald door A. Sizoo. Delft: W.D. Meinema N.V.

Chan, S. 2006. Liturgical Theology. The Church as Worshiping Community. Downers Grove: IVP Academic.

Cilliers, J. 1996. Die Uitwissing van God op die Kansel. Ontstellende Bevindinge oor Suid-Afrikaanse

Prediking. Wellington: Lux Verbi.

Davis, K. 1991. Secrets of Dynamic Communication. Grand Rapids: Zondervan Publishing Company.

De Bono. 1970. Lateral Thinking. London: Penguin Books.

Dingemans, G.D.J. 1991. Als Hoorder onder de Hoorders. Een Hermeneutische Homiletiek. Handboek Praktische Theologie. Kampen: Kok.

Gibson, S.M. 2004. "Introduction - Preaching to a Shifting Culture." In: Preaching to a Shifting Culture.

Twelve Perspectives on Communicating that Connects. Grand Rapids: Baker Books. p.p. 11-15.

Güder, D.L. 2000. The Continuing Conversion of the Church. The Gospel and our Culture Series.Grand Rapids: William B. Eerdmans Publishing Co.

Heath, C \& Heath, D. 2008. Made to Stick. Why Some Ideas Take Hold and Others Come Unstuck. London: Arrow Books.

Hirsch, A. 2006. The Forgotten Ways. Reactivating the Missional Church. Grand Rapids: Brazos Press.

Hunter, C. 2007. "Imagination, Creativity and Preaching." In: The Folly of Preaching. Models and Methods.

Grand Rapids: William. B. Eerdmans Publishing Company. p.p. 86-97.

Jamieson, A. 2002. A Churchless Faith. Faith Journeys Beyond the Churches. London: Society for Promoting Christian Knowledge.

Long, T.G. 1989. The Witness of Preaching. Louisville: Westminster / John Knox Press.

Marty, M. 2007. "Preaching Rhetorically: Thanks Aristotle and Apostles." In: The Folly of Preaching. Models and Methods. Grand Rapids: William. B. Eerdmans Publishing Company. p.p. 98-109.

Maslow, A.H. 1943. "A Theory of Human Motivation.” In: Psychological Review. Volume 50. p.p. 370-396. [Available Online.] http://psychclassics.yorku.ca. http://psychclassics.yorku.ca/Maslow/motivation. htm. [Site accessed: 2010-04-05.]

Mead, L.B. 1991. The Once and Future Church. Reinventing the Congregation for a New Mission Frontier. New York: The Alban Institute.

Miller, M.R. 2004. The Millennium Matrix. Reclaiming the Past, Reframing the Future of the Church. San Francisco: Jossey Bass.

Morgenthaler, S. 2007. "Leadership in a Flattened World. Grassroots Culture and the Demise of the CEO Model." In: An Emergent Manifesto of Hope. Grand Rapids: Baker Publishing Group. p.p. 175-188.

Murphy, T. 1997. Programming with Purpose. Developing a Process for Programming. Grand Rapids: Zondervan Publishing House.

Nel, M. 2001. Ek is die verskil. Die invloed van persoonlikheid in die prediking. Bloemfontein: CLF Uitgewers.

Niemandt, N. 2007. Nuwe drome vir nuwe werklikhede. Geloofsgemeenskappe in pas met 'n postmoderne wêreld. Wellington: Lux Verbi.BM.

Ogden, G. 1990. The New Reformation. Returning the Ministry to the People of God. Grand Rapids: Zondervan Publishing House.

Osmer, R.R. 1990. A Teachable Spirit. Recovering the Teaching Office in the Church. Louisville: Westminster/ John Knox Press.

Peterson, E. 2006. Eat this Book. The Art of Spiritual Reading. London: Hodder \& Stoughton.

Pettersson, R. 1989. Visuals for Information: Research and Practice. Englewood Cliffs: Educational Technology Publications.

Richter, J. (red) 1998. Het ons Harte nie warm geword nie ..? Riglyne vir ‘n Gemeentelike Eredienswerkgroep. Stellenbosch: BUVTON.

Saxby, S. 1990. The Age of Information - The Past Development and Future Significance of Computing and Communications. New York: New York University Press.

Sellers, R. 2004. "Survey: Contemporary Worship Styles Increasing." [Aanlyn]. In: http://www.lifeway.com/ article/156455. [Werf besoek: 2010-03-20].

Senge, P.M. 2006 (revised and updated). The Fifth Discipline. The Art \& Practice of the Learning Organisation. London: Random House Business Books.

Skinner, C.P. 1993. "Sermon preparation and the creative cycle." In: Die Moderne Gemeente en haar Funksionering / The Dynamics of the Modern Church. Lynnwoodrif: Verba Vitae. p.p. 95-105. 
Smit, D. 2009. "Ontdek die eie Aard van die Gereformeerde Erediens." In: Ontdekkings in die Erediens. Wellington: Lux Verbi.BM. p.p. 87-107.

Smit, G.H., 2010, 'Aanbidding en prediking in missionale gemeentes - homileties-liturgiese beskouinge van missionêre gemeentebediening', HTS Teologiese Studies/Theological Studies 66(1), Art. \#313, 6 pages. DOI: 10.4102/hts.v66i1.313.

Stanley, A. \& Jones, L. 2006. Communicating for a Change. Colorado Springs: Multnomah Books.

Sweet, L. 1999. Soultsunami. Sink or Swim in New Millennium Culture. Grand Rapids: Zondervan Publishing House.

Sweet, L. \& McLaren, B.D. \& Haselmayer, J. 2004. A is for Abductive. The Language of the Emerging Church. Grand Rapids: Zondervan Publishing House.

Vos, C.J.A. 1995. Die Blye Tyding. RGN-studies in Praktiese Teologie. Pretoria: Raad vir Geesteswetenskaplike Navorsing.

Wepener, C. 2009a. From Fast to Feast. A Ritual-Liurgical Exploration of Reconciliation in South African Cultural Contexts. Leuven: Uitgeverij Peeters.

Wepener, C. 2009b. “Ontdek eietydse tendense en uitdagings rondom die erediens." In: Ontdekkings in die Erediens. Wellington: Lux Verbi.BM. p.p. 181-194.

\section{TREFWOORDE}

Digitale kultuur

Homiletiek

Kommunikasieteorie

Kommunikatiewe praxis

Missionerende bedieningspraktyk

\section{KEY WORDS}

Digital culture

Homiletics

Communication theory

Communicative praxis

Missional ministry practice

KONTAKBESONDERHEDE

Dr Guillaume Smit

Posbus 195

BRACKENFELL

7561

Tel: 083 306-1561 